\title{
COVID-19-Related Stroke: Barking up the Wrong Tree?
}

\author{
Nicola Morelli ${ }^{a}$ Eugenia Rota ${ }^{b}$ Chiara Terracciano ${ }^{a}$ Paolo Immovilli ${ }^{a}$ \\ Marco Spallazzi $^{a}$ Davide Colombic Domenica Zaino ${ }^{a}$ Arens Taga $^{d}$ \\ Emanuele Michieletti ${ }^{c}$ Donata Guidetti ${ }^{a}$

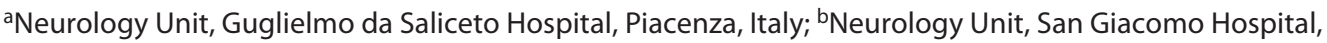 \\ Alessandria, Italy; ${ }^{~}$ Radiology Unit, Guglielmo da Saliceto Hospital, Piacenza, Italy; ${ }^{\mathrm{d} D e p a r t m e n t}$ of Neurology, \\ Johns Hopkins University, Baltimore, MD, USA
}

\section{Dear Editor,}

We are grateful to Hooshmandi et al. [1] (ENE-20204-59) for the interest shown in our article and for their comments. At the time of writing, Piacenza was the second most heavily hit Italian city by COVID-19 pandemic (1.415\%) [2], providing an exceptional perspective of the current situation in the neurological field. We previously emphasized how the main limit of our comments was the brief observation period, that is, 1 month, that is when the outbreak of SARS-CoV-2 peaked. In the following period, only few small case series of COVID-19 stroke patients have been reported [3-8]. Therefore, little information is available on stroke in this unknown pathological scenario.

Despite the lack of current scientific literature on the topic, which is limited to anecdotal reports, numerous hypotheses have been put forward as to the role of the thrombophilic state induced by $2019-\mathrm{nCoV}$ and the likely increased risk of stroke in infected patients [9-11]. From February 21 to April 28, 2020, 854 COVID-19 patients were admitted to our facility, 17 of whom with concomitant ischemic stroke symptoms (mean age $76.1 \pm 8.8$ ). No young adult stroke patient was observed. There was no rare stroke etiology or unforeseen high incidence in stroke subtypes. Severity of stroke evaluated by the NIHSS seems

karger@karger.com

(C) 2020 S. Karger AG, Basel

www.karger.com/ene

Karger! to correlate with extension of interstitial pneumonia documented with chest CT scan (personal data, in press).

However, anecdotal evidence is collected in a casual or informal manner and relies entirely on personal testimony. Therefore, it is generally considered to have a limited value, due to a number of potential weaknesses. For this reason, we agree with Hooshmandi et al. that it is too early to consider a direct "cause-effect" relationship between 2019-nCoV infection and stroke occurrence so that further prospective and large-volume studies are warranted. The occurrence of different types of cerebrovascular diseases during the 2019-nCoV pandemic can be documented only by international multicenter studies. Indeed, the prevalence of COVID-19 is so high in pandemic hotspots that an incidental association between infection and neurological manifestations cannot be excluded.

During a pandemic, when science and medicine are asked to provide answers, neurologists should strive to keep high scientific research standards and place trust in their clinical methods, starting with an accurate patient interview and then moving through standard neurological examination. The clinical path is then completed by

All authors contributed equally to the manuscript. 
the diagnostic confirmation through imaging, laboratory, electrophysiological, and pathological techniques.

All of which leads to the question as to whether relating stroke to COVID-19 may be tantamount to barking up the wrong tree. Hopefully, time and research will be our mentors, as has often been the case.

\section{Acknowledgement}

The authors thank Mrs. Barbara Wade for her linguistic advice.

\section{Disclosure Statement}

The authors have no conflicts of interest to declare.

\section{Funding Sources}

This research received no specific grant from any funding agency in the public, commercial, or not-for-profit sectors. No financial support was provided for the research, authorship and/or publication of this article.

\section{Author Contributions}

Study concepts: N. Morelli, E. Rota, and C. Terracciano. Study design: N. Morelli, E. Rota, and M. Spallazzi, Data analysis/interpretation: N. Morelli, D. Zaino, P. Immovilli, and D. Colombi. Manuscript preparation and definition of intellectual content: $\mathrm{N}$. Morelli, E. Rota, and C. Terracciano. Manuscript editing: N. Morelli, E. Rota, and Arens Taga. Manuscript revision/review: D. Guidetti and E. Michieletti.

\section{References}

1 Hooshmandi E, Borhani-Haghighi A. The Case Is Much More Baffling than We Think. Eur Neurol. 2020. doi: 10.1159/000508598.

2 Available from: https://lab24.ilsole24ore. com/coronavirus/ accessed 2020 Apr 30.

3 Oxley TJ, Mocco J, Majidi S, Kellner CP, Shoirah $\mathrm{H}$, Singh IP, et al. Large-vessel stroke as a presenting feature of Covid-19 in the young. N Engl J Med. 2020 May 14;382(20):e60.

4 Mao L, Jin H, Wang M, Hu Y, Chen S, He Q, et al. Neurologic manifestations of hospitalized patients with coronavirus disease 2019 in Wuhan, China. JAMA Neurol. 2020 Apr 10:e201127. Epub ahead of print.
5 Helms J, Kremer S, Merdji H, Clere-Jehl R, Schenck M, Kummerlen C, et al. Neurologic features in severe SARS-CoV-2 infection. N Engl J Med. 2020 Apr 15:NEJMc2008597. Epub ahead of print.

6 Lodigiani C, Iapichino G, Carenzo L, Cecconi M, Ferrazzi P, Sebastian T, et al. Venous and arterial thromboembolic complications in COVID-19 patients admitted to an academic hospital in Milan, Italy. Thromb Res. 2020 Apr 23;191:9-14. Epub ahead of print.

7 Viguier A, Delamarre L, Duplantier J, Olivot JM, Bonneville F. Acute ischemic stroke complicating common carotid artery thrombosis during a severe COVID-19 infection. J Neuroradiol. 2020 May 4;S0150-9861(20):30159. Epub ahead of print.
8 Beyrouti R, Adams ME, Benjamin L, Cohen H, Farmer SF, Goh YY, et al. Characteristics of ischaemic stroke associated with COVID-19. J Neurol Neurosurg Psychiatry. 2020 Apr 30:jnnp-2020-323586. Epub ahead of print.

9 Siniscalchi A, Gallelli L. Could COVID-19 represent a negative prognostic factor in patients with stroke? Infect Control Hosp Epidemiol. 2020 Apr 20:1. Epub ahead of print.

10 Hess DC, Eldahshan W, Rutkowski E. COVID-19-related stroke. Transl Stroke Res. 2020 May 7;11(3):322-5. Epub ahead of print.

11 Calcagno N, Colombo E, Maranzano A, Pasquini J, Keller Sarmiento IJ, Trogu F, et al. Rising evidence for neurological involvement in COVID-19 pandemic. Neurol Sci. 2020 May 12:1-3. Epub ahead of print. 